\title{
Post-Stroke Epilepsy within a Teaching Hospital in Cotonou, Benin
}

\section{Dieu Donné Gnonlonfoun 1*, Constant Adjien¹, Mendinatou Agbetou², Thierry Adoukonou², Jennifer Mapaga1, Gérard Goudjinou1, Dismand Houinato}

\author{
${ }^{1}$ Department of Neurology, National University Hospital Centre, Cotonou, Bénin \\ ${ }^{2}$ Department of Neurology, National University Hospital Centre, Parakou, Bénin \\ Email: *dieudonne.gnonlonfoun@gmail.com
}

How to cite this paper: Gnonlonfoun, D.D., Adjien, C., Agbetou, M., Adoukonou, T., Mapaga, J., Goudjinou, G. and Houinato, D. (2017) Post-Stroke Epilepsy within a Teaching Hospital in Cotonou, Benin. Neuroscience \& Medicine, 8, 47-52. https://doi.org/10.4236/nm.2017.84007

Received: September 1, 2017

Accepted: December 1, 2017

Published: December 4, 2017

Copyright $\odot 2017$ by authors and Scientific Research Publishing Inc. This work is licensed under the Creative Commons Attribution International License (CC BY 4.0).

http://creativecommons.org/licenses/by/4.0/

\begin{abstract}
Seizures occurring after stroke are risk factors for the onset of ensuing epilepsy. However, the incidence of vascular epilepsy is low. The purpose of this study was to study vascular epilepsy features in a teaching university. It was a retrospective, descriptive and analytical study, conducted from $1^{\text {st }}$ January 2015 to $31^{\text {st }}$ December 2016 in Cotonou Teaching Hospital (CNHU-HKM), Benin. It involved 35 patients brought together through comprehensive sampling. Vascular epilepsy hospital attendance rate was $2 \%$. There were simple partial seizures in $74.28 \%$ of cases while cerebral ischemia was recorded in $44.44 \%$ of patients. Neurological consultation after stroke occurrence was a protective factor against the occurrence of vascular epilepsy with significant $p$ at 0.001 .
\end{abstract}

\section{Keywords}

Post-Stroke Epilepsy, Vascular Epilepsy, Cotonou, Benin

\section{Introduction}

Epilepsy and stroke are two common pathologies which increase in frequency with age [1]. Epilepsy is a chronic disease with $0.5 \%$ to $1 \%$ prevalence. It affects over 150/100,000 patients beyond 80 years [2]. Stroke is the third cause of mortality and the leading source of disability particularly among individuals over 65 years. The association of these two pathologies is not haphazard. Indeed, epilepsy is one of the most common stroke comorbidities [3]. Stroke accounts for $11 \%$ of adult symptomatic epilepsies [4], and beyond the age of 60 , it is the leading cause of epilepsy (33\%) ahead of degenerative diseases including Alzheimer's disease $(15 \%)$, brain tumors (5\%) or brain trauma injury (1\% to $2 \%$ ) [5]. The 
imaging carried out for patients over 60 years of age experiencing their first seizure reveals $21 \%$ of unknown infarction. The prevalence of epileptic seizures following stroke varies from $5 \%$ to $20 \%$ with an average of $10 \%$ [6], however, only few patients will actually develop real vascular epilepsy estimated at 2 to $4 \%$ [7]. This study was conducted in view of studying vascular epilepsy features within a teaching university in Cotonou, to take stock of the various aspects of this disease within our work environment.

\section{Methods}

It was a retrospective, descriptive and analytical study, conducted from $1^{\text {st }}$ January 2015 to $31^{\text {st }}$ December 2016 in CNHU-HKM, Cotonou, Benin. Benin is a French Speaking country in West Africa, sharing borders with Nigeria on the east. It boasts of 9 million inhabitants and an area of $112.622 \mathrm{~km}^{2}$. The study population covered all patients admitted to hospital or attended Neurology during the study period. The inclusion Criteria was any patient hospitalized or followed in consultation of Neurology for a diagnosis of vascular epilepsy.

The diagnosis of stroke was based on the brutal occurrence of a neurological deficit associated with characteristic brain imaging. The diagnosis of epilepsy was based on the repetition of epileptic seizures associated with epileptic grapho-elements with electroencephalogram. The diagnosis of vascular epilepsy was based on:

- Absence of a personal or family history of epilepsy or other epileptogenic neurological disease;

- Repetition of seizures, stereotyped, unprovoked, at least three weeks (21 days) after the stroke and in connection with the stroke;

- In relation with the latter with or without EEG graphic element.

Sample size was calculated using Daniel Schwartz formula $\mathrm{n}=\mathrm{Z} \alpha^{2} \mathrm{pq} / \mathrm{i}^{2}$ with $2 \%$ as the frequency of vascular epilepsies [8] is 30 . But the study finally reached on 35 patients. Data collection was conducted through a compilation form including clinical, paraclinical, scalable, and therapeutic data in addition to socio-demographic data. EPIDATA and STATA/IC 11.0 were used for data entry, quality control and analysis. Comparisons were made using Chi2 and Fisher tests if expected values were below five. The study of associated factors was carried out using the logistic regression model in univariate and multivariate analysis. The multivariate analysis was conducted by introducing into the model, all variables whose $p$ value in univariate analysis is $\leq 20 \%$. Significance threshold was $5 \%$ and confidence intervals were calculated at the rate of $95 \%$.

\section{Results}

On the period, we received 1703 patients. 35 had vascular epilepsy. The frequency of vascular epilepsy was $2 \%$. The sex-ratio was 1.9 . The mean age of patients was $53.49 \pm 18.76(42-85)$ years. Only $8.57 \%$ of the patients were jobless most of them were married $(74.29 \%)$ and $60 \%$ lived in urban area. Table 1 highlights 
Table 1. Major socio-demographic characteristics of the study population, Cotonou 2016.

\begin{tabular}{|c|c|c|}
\hline & Total & Percentage \\
\hline \multicolumn{3}{|l|}{ Age } \\
\hline [40 - 60 years] & 17 & 48.57 \\
\hline$[60-80$ years $]$ & 14 & 40.00 \\
\hline [80 - 100 years] & 4 & 11.43 \\
\hline \multicolumn{3}{|l|}{ Sex } \\
\hline Male & 23 & 66.00 \\
\hline Female & 12 & 34.00 \\
\hline \multicolumn{3}{|l|}{ Profession } \\
\hline Private sector worker & 7 & 20.00 \\
\hline Laborer & 7 & 20.00 \\
\hline Housewife & 7 & 20.00 \\
\hline Retired & 6 & 17.14 \\
\hline Unemployed Trader & 3 & 8.57 \\
\hline Craftsman & 2 & 5.71 \\
\hline Civil servant & 2 & 5.71 \\
\hline \multicolumn{3}{|l|}{ Marital Status } \\
\hline Married & 26 & 74.29 \\
\hline Single & 4 & 11.43 \\
\hline Widower & 3 & 8.57 \\
\hline Divorced & 2 & 5.71 \\
\hline \multicolumn{3}{|l|}{ Place of residence } \\
\hline Urban areas & 21 & 60 \\
\hline Rural areas & 14 & 40 \\
\hline
\end{tabular}

the demographic characteristics of the individuals included in the study.

Among all patients who provided information on their therapeutic itinerary, upon the onset of their stroke $5.70 \%$ consulted a general practitioner, $14.28 \%$ a tradipractitioner and $20 \%$ a neurologist.

Most of our patients had simple partial type of seizures (74.28\%) followed by secondarily generalized seizures (14.28\%). Generalized seizures were observed in $5.71 \%$ of cases. The average number of seizures recorded was $5.83 \pm 3.37$ (1 - 16) per month. Patients have been experiencing seizures for a median period of $21.44 \pm 27(9-48)$ months. Discontinuation of anti-epileptic treatment among the study population was the most triggering factor of seizure recorded (45.7\%).

27 patients (77.1\%) had cerebral CT-scan. Table 2 shows these results.

The EEG was performed in 13 cases. The abnormalities are summarized in Figure 1.

All patients were put under anticonvulsant treatment. Phenobarbital was the most used drug, followed by benzodiazepine derivative drugs respectively in proportion of $57.14 \%$ and $28.57 \%$. A mono, dual and triple therapy was respectively used among $62.85 \%, 25.71 \%$ and $11.42 \%$ of patients. 
Table 2. Distribution of patients according to cerebral CT anomalies.

\begin{tabular}{ccc}
\hline & Effective & Percentage \\
\hline Ischemia & 12 & $44.4 \%$ \\
Hemorrhage & 7 & $25.9 \%$ \\
Leucoaraiose & 5 & 118.5 \\
Lacune & 3 & $1.2 \%$ \\
\hline
\end{tabular}

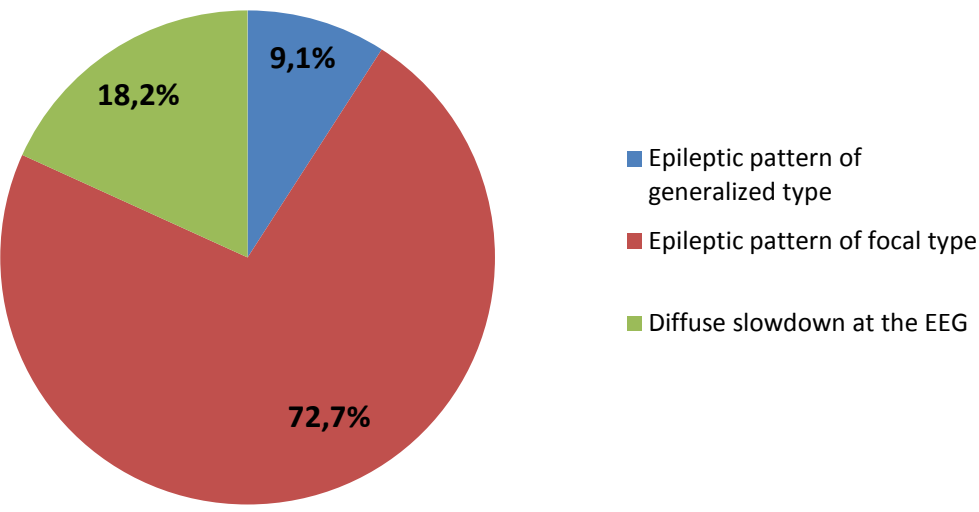

Figure 1. Distribution of patients according to EEG abnormalities.

Upon univariate analysis, it appeared that no socio-demographic variable influence vascular epilepsy. The result of the multivariate analysis is that consulting the neurologist after stroke occurrence influenced vascular epilepsy and was even a protective factor. Table 3 shows this result.

\section{Discussion}

The prevalence of epileptic seizures after stroke is quite low. Similarly, in 2004, Camilo noted a frequency of $2 \%$ to $4 \%$ [9]. However, it could vary from $5 \%$ to $20 \%$ according to Ferro [10]. On the one hand, this gap is explained by the differences in terms of methodology and design from one study to the other; and on the other hand, the variability in the concept of vascular epilepsy [11]. The average age of vascular epilepsy occurrence established at 53 years in our study population is similar to that observed in the literature, and it reflects the age pyramid in our country. In fact, cerebrovascular injuries account for $30 \%$ to $50 \%$ of epilepsies among elderly individuals [3]. Unlike the female predominance observed in Szaflarski series [12], we recorded no such prevalence in our population. Most of our patients were married, and this reflects their good social integration owing to the type of seizure. Partial seizures were less known by the population, and they did not entail social dislocation or stigmatization. There could be any type of partial seizures. Semiology of seizures will indeed depend on the topography of vascular injury [13]. Partial seizures including motor symptoms with or without generalization were prevalent [14]. Patients experienced seizures within a median period of $21.44 \pm 27.48$ months, furthermore, the peak period for developing vascular epilepsy is between the first and 
Table 3. Multivariate analysis.

\begin{tabular}{ccccc}
\hline & $\begin{array}{c}\text { Vascular } \\
\text { epilepsy }\end{array}$ & Gross RC & Adjusted RC & p \\
\hline Neurologist & & & & \\
Yes & $5(9.26)$ & 1 & 1 & $0.001^{\star}$ \\
No & $6(2.29)$ & 1.65 & $0.08[0.01-0.37]$ & \\
Indeterminate & $2(14.29)$ & 9.77 & $1.16[0.19-6.82]$ & \\
\hline
\end{tabular}

*Significant Result.

eighteenth month after stroke occurrence [15]. The average frequency of seizures estimated approximately at 6 seizures per month at the $21^{\text {st }}$ month reflects the difficulties in providing care and support for these patients. The predominance of ischemic stroke found in the brain CT scan [16] is in relation with the general predominance of ischemic stroke in Benin hospital facilities [17]. The rapeutically, phenobarbital was the most used drug in the light of its financial accessibility and scarcity of new antiepileptic drugs in our work environment [18]. Upon stroke occurrence, neurological consultation was the only factor associated with the occurrence of vascular epilepsy. Furthermore, it is a protective factor. This is explained by good care and support for stroke by the neurologist, because of his specific and updated knowledge on this cerebrovascular pathology.

\section{Conclusion}

Clinical aspects of epileptic seizures during stroke are differently perceived according to the studies. Partial seizures are predominant and require early diagnosis as well as care and support from the neurologist as protective factor against the occurrence of vascular epilepsy.

\section{References}

[1] Hamidou, B., Aboa-Eboulé, C., Durier, J., Jacquin, A., Lemesle-Martin, M., Giroud, M., et al. (2013) Prognostic Value of Early Epileptic Seizures on Mortality and Functional Disability in Acute Stroke: The Dijon Stroke Registry (1985-2010). Journal of Neurology, 260, 1043-1051. https://doi.org/10.1007/s00415-012-6756-3

[2] Brodie, M.J. and Kwan, P. (2005) Epilepsy in Elderly People. BMJ, 331, 1317-1322. https://doi.org/10.1136/bmj.331.7528.1317

[3] Lamy, C., Domigo, V., Semah, F., Arquizan, C., Trystram, D., Coste, J., et al. (2003) Early and Late Seizures after Cryptogenic Ischemic Stroke in Young Adults. Neurology, 60, 400-404. https://doi.org/10.1212/WNL.60.3.400

[4] Loiseau, J., Loiseau, P., Duché, B., Guyot, M., Dartigues, J.F. and Aublet, B. (1990) A Survey of Epileptic Disorders in Southwest France: Seizures in Elderly Patients. Annals of Neurology, 27, 232-237. https://doi.org/10.1002/ana.410270304

[5] Hauser, W.A., Annegers, J.F. and Kurland, L.T. (1996) Incidence of Epilepsy and Unprovoked Seizures in Rochester, Minnesota: 1935-1984. Epilepsia, 34, 453-468. https://doi.org/10.1111/j.1528-1157.1993.tb02586.x

[6] Leys, D. (2003) Ischemic Strokes in Young Adults. La Revue de Médecine Interne, 
24, 585-593. https://doi.org/10.1016/S0248-8663(03)00071-7

[7] Dupont, S. and Baulac, M. (2004) Contribution of MRI to the Exploration of Partial Refractory Epilepsy. Revue Neurologique, 160, 5S91-5897. https://doi.org/10.1016/S0035-3787(04)71187-X

[8] Bladin, C.F., Alexandrov, A.V., Bellavance, A., Bornstein, N., Chambers, B., Coté, R., et al. (2000) Seizures after Stroke: A Prospective Multicenter Study. Archives of Neurology, 57, 1617-1622. https://doi.org/10.1001/archneur.57.11.1617

[9] Camilo, O. and Goldstein, L.B. (2004) Seizures and Epilepsy after Ischemic Stroke. Stroke, 35, 1769-1775. https://doi.org/10.1161/01.STR.0000130989.17100.96

[10] Ferro, J.M. and Pinto, F. (2004) Poststroke Epilepsy: Epidemiology, Pathophysiology and Management. Drugs Aging, 21, 639-653. https://doi.org/10.2165/00002512-200421100-00003

[11] Daniele, O., Mattaliano, A., Tassinari, C.A. and Natalè, E. (1989) Epileptic Seizures and Cerebrovascular Disease. Acta Neurologica Scandinavica, 80, 17-22. https://doi.org/10.1111/j.1600-0404.1989.tb03836.x

[12] Szaflarski, J.P., Kay, B., Gotman, J., Privitera, M.D. and Holland, S.K. (2013) The Relationship between the Localization of the Generalized Spike and Wave Discharge Generators and the Response to Valproate. Epilepsia, 54, 471-480. https://doi.org/10.1111/epi.12062

[13] Vercueil, L. (2007) Seizure and Epilepsy after Stroke. Presse Medicale, 36, 176-181. https://doi.org/10.1016/j.lpm.2006.11.001

[14] Kremer, S., Minotti, L., Thiriaux, A., Grand, S., Satre, V., Le Bas, J.-F., et al. (2003) Epilepsy and Hypothalamic Hamartoma: Look at the Hand Pallister-Hall Syndrome. Epileptic Disorders, 5, 27-30.

[15] Hildebrand, J., Van Bogaert, P., Tugendhaft, P. and Thiriaux, A. (2002) Drug Treatment of Epilepsy. Revue Medicale De Bruxelles, 23, 500-503.

[16] Gnonlonfoun, D., Adjien, C., Ossou-Nguiet, P., Mapoure, Y., Houinato, D. and Avode, D. (2013) Frequency of Neurology Deseases in CNHU-HKM of ${ }^{2}$ Cotonou. Journal De La Societe De Biologie, 18, 43-48.

[17] Adoukonou, T., Kouna-Ndouongo, P., Codjia, J.-M., Covi, R., Tognon-Tchegnonsi, F., Preux, P.-M., et al. (2013) Direct Hospital Cost of Stroke in Parakou in Northern Benin. The Pan African Medical Journal, 16, 121-125.

[18] Houinato, D., Adjien, K.C., Gnonlonfoun, D., Adoukonou, T., Chabi Iranin, I. and Avode, D. (2007) Study of Epilepsy Prevalence in Dangbo (Benin). Le Bénin Médical, 14, 14-17. 